\title{
Development power: the potential dynamics in economic process
}

\author{
Feng Dai*, Songtao Wu, Ling Liang \\ Department of Management Science, Zhengzhou Information Engineering University, Zhengzhou, China
}

Email address:

fengdai@126.com (F. Dai),wst126@126.com (Songtao Wu), liang_ling@163.com (L. Liang)

To cite this article:

Feng Dai, Songtao Wu, Ling Liang. Development Power: The Potential Dynamics in Economic Process, International Journal of Economics, Finance and Management Sciences. Vol. 1, No. 1, 2013, pp. 25-37. doi: 10.11648/j.ijefm.20130101.14

\begin{abstract}
Stating from the intrinsic characteristics of macroeconomic development, this paper puts forward the concept of development power and its theoretical frame. The development power is the potential and invisible dynamics to promote economic growth. By means of the development power theory, we can explain some important problems in macro-economy. We discuss the basic properties of development power and obtain some results, such as, the effects of economic policy depends on the development power, the imbalance of economic development is caused by the different levels in development power. The method is given to evaluate development power, and then we may analyze the mutual effects among development powers. Finally, we illustrate that the development power movements exist widely in the economic development.
\end{abstract}

Keywords: Economic Development, Development Power, Theoretical Frame, Evaluating Index, Time Series

\section{Introduction}

There are many of the important achievements of economic theory, such as the business cycle theory[1,2], the real business cycle theory[3], the new growth theory[4,5,6], and the prospect theory[7], etc. These theories has availably promote the world economic development. Here, author try to make a discussion on the invisible and potential power hidden in economic development. The power, referred to as the development power, is very important to control the economic growth or recession. We may feel that it exists anywhere, anytime and in many ways. But, there seems no many special researches about it yet now.

\subsection{The Current Economic Theories}

Lucas used the time series analysis based on the theory of rational prospect, and demonstrated the Philips curve[8], this means that the economic development follows an equili-brium cycle, and the cycle changes with the government policy. The economic cycle is ineluctable, but the govern-mental interfere will finally be out of order. The new classical school quickly grew up at 20th century 80's, Kydland et al bring forward the real business cycle theory $[9,10,11]$. The real business cycle theory still completely followed the Lucas' research route in the economic cycle research, and used the complete economic person as a basis, and designed the economic system laboratory in order to avoid the expensive experimental fee for actual economic policy. Therefore, Lucas is still the most important person to the real business cycle theory. Another famous research from Lucas is his proposition about policy invalidation, i.e., the famous Lucas' "A Critique" (1976)[12] Lucas pointed out: only if the construction of quantitative economic model is consistent with the optimal decision rule of economy individual, and the optimal decision rules change along with the variety of the environments around the decision maker, then the economic policies would change systematically the con-struction of quantitative economic model. This proposition is a rigorous challenge to the foundation of quantitative model of macro-economy prevailed at that time.

In 20th century 80 's, another important progress in the field of macroeconomics is the new growth theory. Romer and Lucas established a theoretical foundation of the new economic growth theory. They think that the market condi-tion of realistic economy is incompletely compete, thus the scale income gradually increase, this kind of result is ob-tained depended on the accumulation of manpower capital. And then, they regarded the endogenesis, accumulation and growth of manpower capital as the headspring and the power for economic growing. In other words, knowledge accumulating, technique innovation and professional manpower capital can not only make themselves growing, and but also make the economy growth be continuous. Kydland and Prescott think, that the 
economic fluctuation is just nature action of real output of production, the reason that economy fluctuates is a result of technique advance, and put forward the real business cycle theory. But some others think: in short-term, there is no certainly causality between the fluctuation of economic output and a technique advance; that the productivity and output are all descending at the economic crisis can't be explained by technique retrogress; also the bigness influence of changing of monetary policy to economic output fluctuation is under no consideration. Therefore, most of economists do not think that the theory can sufficiently explain the reason for fluctuating on economic output.

The traditional economics thinks that a "rational eco-nomic person" (Simon, 1954)[13] can estimate the emer-gence possibility of different future results, and then max-imize its expectation utility. This kind of "expected utility theory" is widely applied in the economic field. Kahneman et al. completed a lot of experiments and investigations $[14,15]$, all the results indicate: the assumption about "ra-tional economic person" deserves a doubt. Thus the "pros-pect theory" is established and the assumption about "non-rational economic person" is put forward, and by the comparison experiments, most of the individual are not always rational and aversion of risk. This means that the problems with which persons have faced will influence their decisions or behaviors.

Is there any way to generalize the theories above?

\subsection{The Problems and Considerations}

Despite all of economic theories above contain its real excellent contents, there still are some problems which are difficult to explain. Such as:

(1) Why the economy will develop? If the reason is social demands, what is the dynamics to bring the social demands?

(2) Can we confirm that there are cycles in the economic development? If there are, we may ask:

- What is the reason to cause the cycle in economic de-velopment?

- What are the characteristics of each stage in economic cycle?

- Are there any different characteristics of dynamics and vitality in each stage of economic cycle?

- How we estimate the time span of each cycle in moving way?

(3) Policys interfering is effective to economic growth or not. If being effective, How long the policys are effective? If not, in which case the interfering policy is not effective ?

(4) Economic output is an objective reality, but what is the real reason for fluctuation in economic output? Is social demands, techniques or policies?

(5) There are the equilibrium phenomenon in the economic development. This also means there are nonequilibrium. How the equilibrium and non-equilibrium are coexistent, corresponded and converted one another?

(6) The assumption and the behavior of "rational economic person" are in conflict with those for "non-rational. What is the case they are conflict one another, and what is not the case?

Is there any theory to describe and explain the problems mentioned above in overall way? Aiming at some current perplexities in economic theory, this paper try to bring forward the theoretical frame of development power. The development power is defined as the invisible dynamics to put economic growth, and is put forward by Dai, Wu \& Qin [16].

The productivity, as we know, is the visible and physical ability to produce goods, but the development power is the immaterial dynamics to improve economy. The intuitive description is that the development power is the "software" of economic development if the productivity is regarded as the "hardware". The development power exists in economic feilds in the forms like policy and system, science and technology, knowledge and education, market system, economic management, law and regulation, consumed desires, etc. The development power is always changing. The development power changes in two way, i.e., accumulating and releasing. The changes of development power promote the productivity to progress and the economy to develop continuously.

In the following, we shall give a discussion about the development power in its cases, concept, theoretical frame and measurement models. We shall see that the development power is widespread to exsit in the economic fields. And it could help us to analyze the economic problems in a differed view with the current way.

\section{The Theory of Development Power}

\subsection{The Basic Cases and Analysis}

In general, economic problems (such as production in confusion, commercial cheat, financial crisis, increase in unemployment, etc.) occur, the demands to solve the prob-lems also come into being, and become stronger and stronger along with the problems becoming more and more serious. Finally, part or all of the demands may be satisfied until the problems are solved. Therefore, some new problems will occur. If there is a dynamics which bring the demands to solve the problems, the dynamics is invisible and comes from the problems. This dynamics is just the development power. Also we may call it the economic development power. The development power is accumulated when the problems become more and more and the demands to solve problems become stronger and stronger. When the problems are being solved and the economic development is going on the right lines, development power is releasing. The accumulating and releasing are the two basic ways of development power movement.

The economy is growing if the demands to solve the problems are satisfied very well, i.e. development power is accumulated or released very well. We may think that the development power and the movement of it promote the economic growth at the moment. Of course, the economic development may be in recession if the problems cannot be 
solved very well. The development power may cause the economy to decline. In fact, the economic growth and re-cession are all the results of development power movement. Further, we have the following examples about development power.

\subsubsection{The Development Power in the Process of Renovating a Policy}

Human needs to establish many policies and to carry out them to maintain the economic growth. Although the poli-cies may be able to promote most of the economic industries to develop very well in some time, there are always some problems of industrial development need to be solved, such as industrial policy, price policy, production and sale policy, financial policy, tax policy, interest rate policy, etc. Of course, many new problems of policy will occur continuously.

In the process of policy establishment, we need to do away with some policies if they are not available to eco-nomic development and establish some new policies if needed. A policy will make some troubles to economy when it is not suitable. At the beginning, the demands to modify the policy or to replace it by a new one do not very strong when it makes some small troubles only. The demand will become stronger and stronger along with the policy making more and more troubles. Finally, the troubles disappear when the policy is modified or replaced by a new one. And then, other policies will need to be modified or replaced. And this process will not end.

We may think there is a dynamics which brings the de-mands to modify or replace an older policy. The dynamics is just the policy development power, and is invisible and caused by the troubles of older policy. The policy devel-opment power is accumulated while the policy troubles become more and more and the demand to modify or replace it becomes stronger and stronger. The troubles will disappear if the policy is modified or replaced, and policy development power is releasing. This is also the process of policy level getting higher and higher, and the way how development power promotes the policy to progress.

\subsubsection{The Development Power in the Perfecting a System of Laws and Rules}

The system of laws and rules is very important to the so-cial and economic development. The changes in economic system at 1978 should be the key for the latter Chinese economic growth.

From 1979 to 2004, the National People's Congress of China deliberated the 323 laws, 212 of them are effective at that time; State Department of Chinese has established 970 administrative laws, 650 or more of them are effective at that time; The legislatives of People's Congress have estab-lished ten thousands or more of regional laws, 7500 or more of them are effective latter (Date source Web,: http:// www.people.com.cn/GB/paper85).

So we see that a perfect system of laws and rules (system for short) is the basis of high economic growth. In fact, the number of economic laws and rules is rising quickly after the 1978's economic reforms in Chinese.

If an economic system is not perfect, there must be some of irrational factors and phenomenon in economy. At the beginning, these factors and phenomenon do not make a larger influence on economy or society, and no new laws and rules need to establish. When the effects of the factors and phenomenon become larger and larger, the demand to perfect system of laws and rules gets stronger and stronger. Finally, the some new laws and rules are established and the factors and phenomenon disappear. Afterward, some other irrational factors and phenomenon occur, and will disappear due to some new laws being established. This process will not end.

We may think there is a dynamics which brings the de-mands to perfect the laws system of economy. The dynamics is just the law and rules (L\&R) development power, and is invisible and caused by the lack of law and rule in economic system. The L\&R development power is accumulated while

the irrational factors and phenomenon become more and more and the demand to establish new laws and rules gets stronger and stronger. The irrational factors and phenome-non will disappear if new laws and rules are established and carried out, and L\&R development power is releasing. This is also the process of economic system becoming more and more perfect, and the way how development power pro-motes the economic system to get better and better.

\subsubsection{The Development Power in Running a Business}

One enterprise manager wants to be successful in the modern economic society, it needs to do well in producing techniques and production management. Both techniques and management not only are the dynamics of enterprise development, but also cause the problems in enterprise operation.

(i) The enterprise production must hold the technique (include the techniques for producing products, techniques of equipments, etc). If an enterprise is in lack of some kinds of new techniques, it seems not to feel that the techniques should be held at the beginning. Afterwards, the enterprise will feel stronger and stronger in holding some new pro-duction techniques because of products and market competition. Finally, the enterprise holds some new techniques and applies them into its production. The production level is higher and the enterprise managers feel the smaller pressure. The pressure occurs and becomes stronger means the technique development power occurs and is accumulated. And the pressure becomes lower means the development power is being released.

(ii) The basis of better operation of an enterprise is the effective management (include the perfect system, the suitable relation between production and sale, the harmonious relation between sharing the works and cooperating with one another, etc). If an enterprise is not good in its management, it may not improve its management 
at the beginning. Afterwards, the enterprise will feel stronger and stronger pressure in improving its management when the confusions occur and the production cannot run normally. Finally, the new management methods have been carried out and the confusions disappear. The confusions occur and become more and more severe means the management development power occurs and is accumulating. And the confusions becomes less means the development power is being released.

\subsubsection{A Preliminary Comments about Development Power}

From the examples above, we should see that

(1) Development power exists widely in economy, society and many other fields.

(2) Development power is a kind of dynamics, also a kind of energy.

(3) Development power may promote economic growth, social progress.

(4) Development power occurs, accumulates and releases based on the changes in environments around it.

In reality, there is development power in many fields, such as consumer demand for commodities, prospect and actuality, consciousness and behavior, work and leisure, reorganization and expansion in economic field, etc., or say that we can use the idea of development power accumulating and releasing to explain the potential energy movements in the former activities.

\subsection{The Theory of Development Power}

Here, we give the formal definition of development power and related interpretations.

\subsubsection{The Concept of Development Power}

Definition 1. The development power is the potential and invisible dynamics to promote economic growth.

The development power can impel the various economic resources to convert to the visible productivity, include the products and serves in society or economy. Development power play the role to impel some exogenous resources to endogenous resources, for examples, transforming the na-tional macroeconomic policies to some policies or rules of industries, transforming the general and basic technology to the producing and equipment techniques in economic pro-duction, etc.

As a kind of dynamics, development power exists and moves based on the three basic points:

- The environments of enterprise production change continuously.

- The environments of economic resources change con-tinuously.

- The natural environments of society and economy change continuously.

All the changes in the environments are just the dynamics themselves. Here, the environments include the products and consumption market. These dynamics comes from peoples' demand, and these dynamics cause society and economy to progress. These dynamics are the development power.
In essential, the development power creates based on the movements of economic environments, and may be the changes in policy and system, science and technique, laws and rules, management, innovation, information, cultural, knowledge, consciousness, idea, spirit and other invisible social and so on. We call these the development power elements. The productivity is the visible behavior ability for human to improve the nature, and the development power is the invisible behavior dynamics for human to improve the nature. In the economic society, development power is the behavior dynamics to develop economy.

The emergence of a new technique is the inevitable out-come of technique development power accumulated, and the application of the new technique means the development power is released. Also, Introduction of a new policy is an inevitable outcome of policy development power being accumulated, and a policy is applied to practice means the development power in the policy is being released. The production level is a measurement of productive ability, and similarly, the developing energy is the measurement of development power.

\subsubsection{The Behaviors of Development Power}

Definition 2. Accumulation of development power is a movement process in which development power becomes stronger and stronger, release of development power is a movement process in which development power is con-verted to other kind of power, and becomes weaker and weaker.

Development power (simply as Developower) can be evaluated by the developing energy in economy. The de-velopment energy becomes larger and larger when the de-velopment power is accumulating, and the development energy becomes smaller and smaller when the development power is releasing. Development power may accumulate, release, re-accumulate, and re-release, so it will drive the society and economy to develop continuously.

If we divide the visible economic resources into the visible nature resources (such as ecological resources like forest, river, land, etc., and raw materials like mines, coal, petroleum etc.); and the visible social resources (such as the manpower, workshops, equipments, surplus product of society, etc.), then the basic way and process of economic development power promoting the conversion from the visible economic resources to the productivity and products can be drawn in Fig. 1.

The accumulation and release are the behaviors of de-velopment power, and the convergence and diffusion are the manners of development power movement.

For example, the development of the computer industry makes the computers being used widely, and the usage of computer causes other industries to develop, such the industries as manufacturing control, weather analysis, spaceflight engineering, scientific simulation, etc. This process is a diffusing on development power. As for manufacturing control, the application of computers can bring about an advance in technique ability of 
manufacturing control, i.e. development power of manufacturing control being accumulated efficiently, so that the productivity of manufacturing control is propelled forward; and if the products of manufacturing control based on computer are applied to producing process, and achieve a good actual results, thus development power of manufac-turing control starts releasing. Afterwards, the higher request to computer from manufacturing control will influence or change the computer industry again, i.e., accumulate the development power of computer industry again. A con-verging process is completed after the case of manufacturing control is occurred to weather analysis, spaceflight engi-neering, scientific simulation, etc. and all of these influences even changes the computer industry with together again. Furthermore, the development of manufacturing control will propel the its downstream industries forward, such as spin and weave, paper making, steel industry, machine and electronics, etc., this is also a diffusing process. After this, another converging process will be occurring. All of these can be described by Fig. 2 .

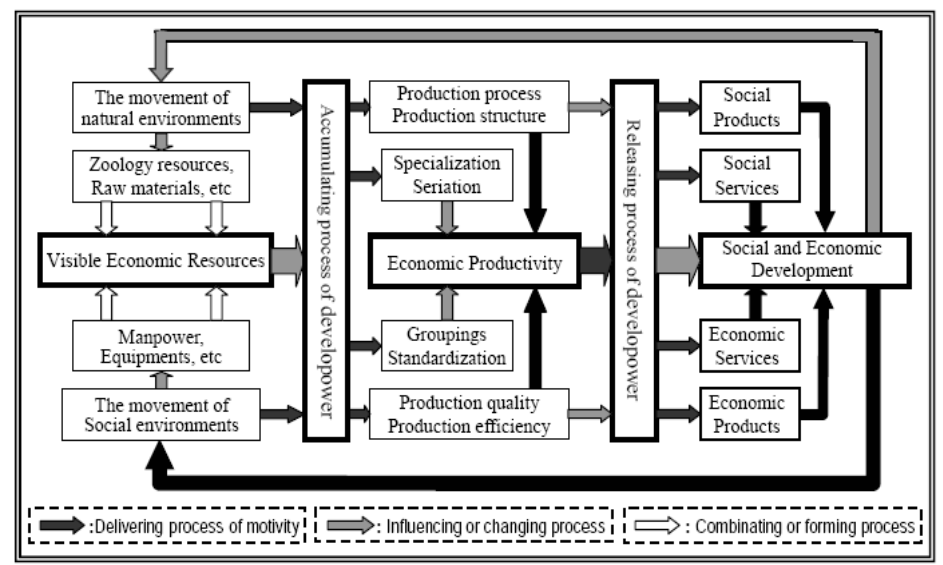

Figure 1.The development power driving the conversion from the visible economic resources to the productivity and products.

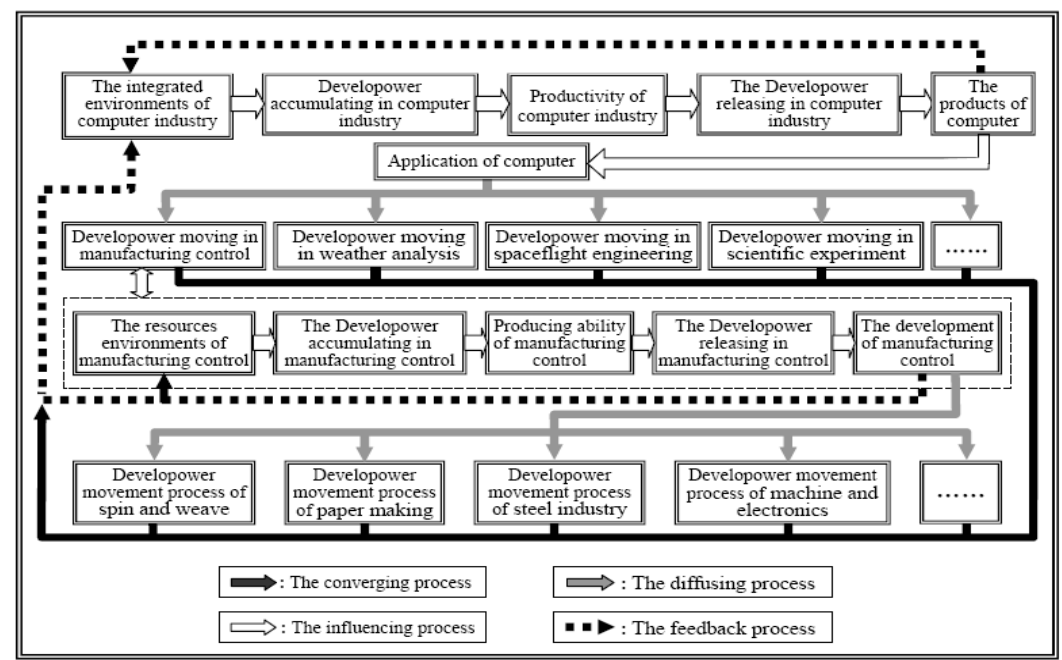

Figure 2. The diffusion and convergence of development power in computer industry. Development power of computer industry, as an underlying development power, could be diffused to other industries, and the development power of those other industries might be accumulated along with underlying development power accumulating. After being accumulated, the development powers should be released. And then, the information of these development powers will be converged and fed back to underlying development power and a new similar process started again.

Definition 3. A derivative process is a stage in process of development power movement. It includes two movements of development power, i.e., an accumulating process and a releasing process.

In general, the movements of development power could compose one or more derivative processes, and could reflect the economic cycle. We shall describe the derivative process on the models of partial distribution afterward.

\subsection{The Basic Results of Development Power}

According to the basic cases, definitions and analysis, we give some basic results and the evaluated method about the development power below.

\subsubsection{The Basic Properties of the Development Power}

In the meaning of physics, the force is a kind of energy, i.e., force exists just because there is the energy contained in it. So, development power is a kind of developing energy. For the sake of convenience, we do not distinguish development power from development energy in the following description. 
(1) development power is a primitive force to promote economic development. Any development and change in economic field are the results of the movements of devel-opment power.

(2) development power is always changing, stronger or weaker. The economy or society is full of vitality is cor-responding to its development power is larger, and vice versa.

(3) The formation and increase of development power depend on it accumulates. When development power is small to a certain degree, it naturally requires to accumulate. If the development power accumulates for a long time, it will be stronger.

(4) After the development power accumulates to a higher degree, it will release out in a certain way. The quicker the development power releases, it is stronger.

(5) The moving cycle of development power. A standard cycle of development power is a derivative process, i.e., includes an accumulating process and a releasing process.

(6) The movement structure of development power. For the movement of development power, a complete cycle includes many shorter or basic cycles. Whether the move-ment cycles of development power are longer or shorter, they are alike in structure, includes a processes of accumulation and a process of release.

\subsubsection{The Basic Results of the Development Power}

According to former analysis on development power and derivative process, we have the following results:

(1) Economic development depends on the accumulation and release of development power. The accumulation of development power will lay a better foundation to develop economy; and the release of development power will pro-mote economy to grow. The key to decide the economic growth rate is that the productivity increases efficiently aroused. Basically, the increase of economic productivity depends on releasing the development power reasonably when it is higher. The reasonable way to release the devel-opment power is effectively implementing economic poli-cies, using management measure, and applying some new techniques.

(2) The process of economic development is a derivative process. The process of economic development is essentially a process that development power becomes weaker or stronger. Both the economic growth and the recession are the derivative processes in which accumulation and release of development power are interlaced. In the economic growth with accumulation of development power, development power becomes stronger and stronger to promote economic growth; and in the economic growth with release of development power, development power becomes weaker and weaker to promote economic recession.

(3) The economic development causes derivative process to be more efficient. With the increase of productivity, production trends to be more standard, special and technical. The standardization is beneficial to accumulate or release development power, so the derivative process is more efficient. On the other hand, the standardization will cause development power to become weaker more quickly. At this time, the main way to accumulate development power is to push the standardization to a higher degree, and to come into a more high-efficient derivative process.

(4) The macroeconomic development is a cyclical process in development power movements. All kinds of economic parts, such as a firm, enterprise group, economic industries, even an economy, have their own cycle of development power movement. When these cycles are synchronous, the macroeconomic development will be obvious in its cycle; if these cycles are not synchronous, the macroeconomic de-velopment will be not obvious in its cycle. Whether the cycle is obvious or not, we cannot deny there are cycles in development power movements, so that we cannot deny there are cycles in macroeconomic development. Therefore, the integrated development power constituted on all those parts promotes the macroeconomic growth and results in the cycle of macroeconomic development. If the development power in a part is exhausted and cannot be accumulated again, the economic development in this part may go to its end.

(5) The effect of economic policy on growth depends on its development power. In fact, the government's policy is effective to economic development in the many cases. That the interfering effect of economic policy is good or not de-pends on the current status of policy development power. If policy development power accumulates sufficiently, the policy will be effective, and if policy development power has released sufficiently or do not accumulates yet, the influence of policy will be weaker, and even no effect.

(6) The imbalance of economy development is caused by the disequilibrium development power. The different coun-tries or different regions have their different economic backgrounds (economic level, economic consciousness, cultural environment, technical level and economic system, etc.), and different abilities to accumulate or to release de-velopment power. In the developed countries or regions, there are the good economic backgrounds to enable their economic development power to accumulate or release effectively, so that their economy could develop to a higher level. But, the poor nations or regions cannot do well in their economy because the development power level is lower, i.e., they have the lower abilities to accumulate or release de-velopment power. The development power level is hard to improve in a shorter time, and it depends on an good envi-ronment which needs to be developed for a long time. So the difference in development power between the developed and poor nations or regions is the basic reasons that there is a big difference in their economy.

(7) The fluctuation of development power decides the fluctuation of economic output. The fluctuation of devel-opment power is caused by the change of economic envi-ronment, and also influences the economic output. So the fluctuation of the economic output is caused by devel-opment power, and lags the fluctuation of development power. Therefore, the fluctuation of economic 
development power is a real reason for fluctuation of economic output.

(8) Modern economic development is more beneficial to the emerging industries. The economic growth which is promoted by accumulation or release of development power can bring the benefits and the opportunities to some indus-tries, also can bring the risks to some other industries. The industries that acquire the benefits are usually the emerging industries, and the traditional industries may suffer loss. Because development power of the traditional industries accumulates and releases again and again, the industries will be more and more hard to accumulate development power if they do not develop their new products.

(9) Development power decides the individual economic behavior. In economy, whether is a "rational economic person" or "non-rational economic person", his economic behavior is decided by his economic environment, con-sciousness, idea, knowledge, experience, and so on. The different consciousness, idea, knowledge and experience may cause the differences in their development power, and these differences may make them show the different beha-viors.

(10) Development power may be high even if the real economic level is low. If the economy of a country or region suffers a blow from a war or nature disaster, and its visible production may disappear, and then its real economic output may be near or equal to zero in a short time. If there are peoples in the countries or regions, their experiences, consciousnesses and techniques means their development power is higher. The higher the development power of a country is, the quicker the rebuilding of the countries or regions is after a war or a nature disaster. The rebuilding of Germany or Japan after War II is just the examples.

\section{The Basic Approach and Model}

If want to use the development power theory to analyze the economic problem, we need to know the approaches to accumulate and release development power and have an model to evaluate development power. We give the discus-sions below.

\subsection{The Basic Approaches to Control the Development Power}

That development power is effectively controlled de-pends on the approaches to accumulate or release it.

\subsubsection{The Main Approaches to Accumulate Development Power}

What we need to indicate is, that the development power is efficiently accumulated and released should match with an appropriate and reasonable way. For example, if a policy to be designed is not appropriate to its real circumstance, the policy development power will not be efficiently accumu-lated, and if an actualized policy can't be accurately un-derstood and used, then it is difficult for policy to produce ideal effect, namely the policy development power being accumulated can't be efficiently released. In general, we have the approaches to accumulate development power as follow.

(1) The positive innovation for economic system. The economic system plays an enormously important role to control the economic development. This function is radically produced from the system development power. Making a continuous innovation on economic system, and insuring the economic system being reasonable and efficient, will allow the system development power to be accumulated continuously, and enable the different branches of economic society to be always coordinated one another, so that the economy could keep on growing.

(2) Perfecting continuously the economic policies and laws. The perfection of economic policies and laws can promote the economy to develop in right direction. This function of economic policies and laws is the policy devel-opment power. Therefore, we may acquire the development power to accelerate economic growth by renewing and perfecting the policy and laws system continuously.

(3) Establishing effectively the innovating mechanism in science and technology (S\&T). The developing vitality of an economy comes from that many new products go into market, and new products are the results of the application of various new science and technology. Just the kind of force from science and technology is the development power of science and technology, which promotes economic devel-opment. So we must establish the innovating mechanism in science and technology, propel science and technology forward, and translate the results of new science and tech-nology to new economic products, namely accumulate the S\&T development power continuously, in order to get the inexhaustible power of science and technology for economic development.

(4) Developing the system of economic education. The good education system and the practice environment in economy will make peoples those who are engaged in the economy learning the necessary knowledge, and gain the worthy experience. Those peoples may use their knowledge and the experience to promote the economic development. So the knowledge and experience are a kind of power, is called the knowledge development power. Therefore, es-tablishing a complete system of economic education is very important for improving the national economic environment, accumulating the knowledge development power effectively, and lay a good foundation for the economic development.

(5) Standardizing the pattern and optimizing the structure in economic management. Standardizing management in economic departments plays important and non-replaceable parts in promoting economy to develop orderly and effectively. We could regard this function of Standardizing management as the management development power. Therefore, management development power will be accumulated effectively if we make a positive innovation in 
standardizing the economic management and in optimizing the hierarchical structure of economic departments, so that the developing power in management will be obtained to push forward the economic progress.

(6) Designing and completing the large scale and com-positive projects. A large scale and compositive project may affect the status of economic development as a whole. Just the power of large scale projects which push economy for-ward is a project development power, e.g. both the success in application and celebration of Olympic Game'2008 and the successes in launching and returning of spaceflight airship with person at 2003 are all the better ways to accumulate project development power for Chinese economic de-velopment.

Just the process of launching the projects mentioned above is the accumulating process for national economic development power. Of course, there are many other ways to accumulate economic development power.

\subsubsection{The Main Approaches to Release Development Power}

Based on the works done above, we have the new or im-proved systems of economy, new economic policies and laws, new innovating mechanism in science and technology, new or improved system of economic education, standard and optimal management in economy, and other things in that development power are accumulated. At this time, the economic systems and environments are better and ordered, economy starts developing in a good process, and the de-velopment power which had been accumulated starts re-leasing. In the releasing process of development power, the economy will have a stable and healthy development until development power is released sufficiently, and then a new accumulating process of development power starts.

The process of accumulating and releasing development power is shown in Fig. 3.

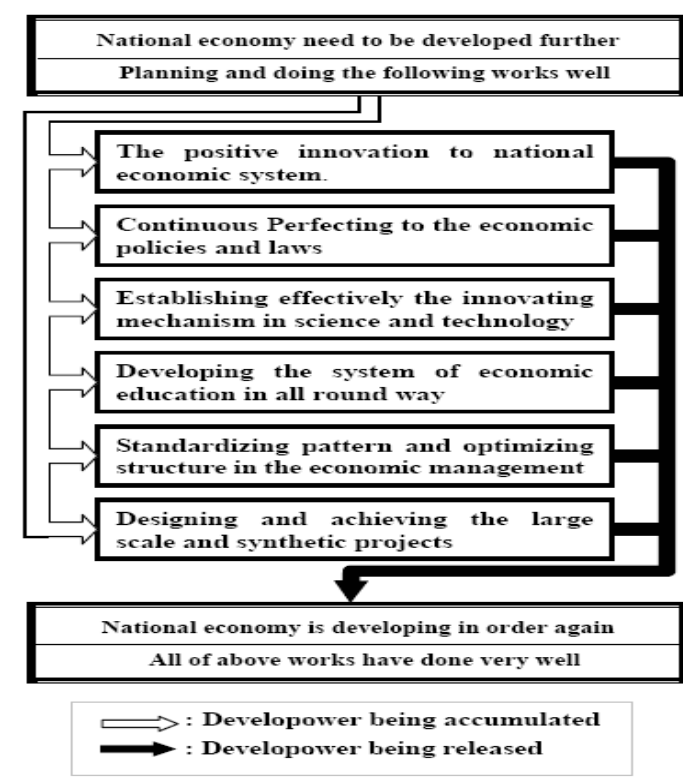

Figure 3. The approaches to accumulate and release development power and their processes. Development power is the invisible dynamics for developing economy, and it include policy, science and technology, education, knowledge, management, systems and laws, culture, idea, etc. There are many other ways for accumulating and releasing beside those listed in this figure.

\subsubsection{A summary}

In Fig. 3, we describe the approaches and process of ac-cumulating and releasing development power. In short, the development power is accumulated by the synthetic inno-vations, and released by the applications of the synthetic innovations. The change in development power means the change in economic energy, and the fluctuation of economic energy influences the economic growth or recession. Both the economic growth and recession need to be pushed by the dynamics and energy. Development power is the dynamics and energy.

\subsection{The Model of Evaluating Development Power}

Here, we should define the economic level as follows.

Definition 4. The economic level is the integrated status of all industries in economic fields, and includes the basic economic level and the real economic level. The basic economic level is the measurement of inherent ability of current economy (basic level for short). The real economic level is the measurement of real economic output (real level for short).

The basic level is determined by the current capital and labour, and may be measured. The real level is stochastic, it is determined by basic level, development power and eco-nomic environment. In a certain period of time, the basic level is the economic level at the beginning, and the real level is the economic level at the end. So the real level of the current period of time will be the basic level of next period of time.

Assumption 1. The assumptions about the economic level are as follow:

(1) Both the basic level and the real level are all nonneg-ative. Namely, the smallest values of the basic level and the real level are the zero.

(2) The real level fluctuates around its basic level, and the fluctuation range is positive, namely the smallest value of the fluctuation range is larger than zero.

(3) The basic level and the fluctuation range of it are the constants. The real level can't be foreknowledge, so it is a stochastic variable.

(4) The possibilities that the real level is much lower than $\mathrm{t}$ the basic level, or is much higher than the basic level, will be very small.

Here, we give the rules about the evaluating the economic level and development power below:

(1) The basic measuring index of the real level is the in-tegrated status of economic development and is generally the GDP (gross domestic product).

(2) The basic measuring scale of development power is generally the development energy, and can be evaluated by the fluctuating range of the economic output, namely stan-dard variance of the economic output. 
(3) In particular, we can also measure the development power by development power index. Development power index describes the relative development power (i.e. the relative development energy). The relative development energy is also called the development vitality. Development power index is the proportion of standard variance of real level to real level, namely

$$
D P I=\frac{\text { The standard variance of the real level }}{\text { The real level }}
$$

As we know, the process is called the economic growth with the accumulation of development power, if real level grows when development power accumulates. The process is called the economic growth with the release of development power, if the economic level grows gradually when development power releases. If the real level declines gradually, we have the economic recession with the accu-mulation of development power and the economic recession with the release of development power. If the real level is stable, we have the economic stability with the accumulation of development power, or the economic stability with the release of development power.

\section{The Partial Distribution and Economic Results on Development Power}

According to the above discussion on development power, we may explain many economic phenomenon and solve some problems in economy. If we want to do all of those better, an appropriate analytic model is necessary based on the partial distribution. Now we give the definition of the partial distribution and some related results below.

\subsection{The Definition of Partial Distribution}

Definition 5 (Partial Distribution). Let $X$ be a non-negative stochastic variable, $\mathrm{X}$ is called to follow a Partial Distribution if it follows the distribution of density:

$$
f(x)= \begin{cases}e^{\frac{(x-\mu)^{2}}{2 \sigma^{2}}} / \int_{0}^{\infty} e^{\frac{(x-\mu)^{2}}{2 \sigma^{2}}} d x & x \geq 0 \\ 0 & x<0\end{cases}
$$

and note as $X \in P\left(\mu, \sigma^{2}\right)$ [17].

We will use the following basic notations:

$\mu$ - the basic level in economy.

$\sigma$ the fluctuation of the basic level, i.e. the standard variance of the basic level. $\sigma$ can be applied to evaluate development power. In some time, we also use the development power index $\sigma / \mu$ to evaluate the strength of relative development power.

$X$ - the real level of economy.

Based on assumption 1 and definition 5, the real level follows the partial distribution, i.e. $X \in P\left(\mu, \sigma^{2}\right)$. If the objects discussed is related to time, then the above notations can be expressed as $\mu(t), \sigma(t)$ and $X(t)$ separately. In the following discussions, we do not distinguish $\mu, \sigma$ and $X$ with $\mu(t), \sigma(t)$ and $X(t)$.

\subsection{The Related Results on Partial Distribution}

Let the real level $X \in P\left(\mu, \sigma^{2}\right)$, the expectation value of the real level $X$ is the average value of the actual level below [18]:

$$
E(X)=\mu+\sqrt{\frac{2}{\pi}} \frac{\sigma e^{-\frac{\mu^{2}}{2 \sigma^{2}}}}{1+\sqrt{1-e^{-\frac{2}{\pi}\left(\frac{\mu}{\sigma}\right)^{2}}}}
$$

where, $R(X)=\sqrt{\frac{2}{\pi}} \frac{\sigma e^{-\frac{\mu^{2}}{2 \sigma^{2}}}}{1+\sqrt{1-e^{-\frac{2}{\pi}\left(\frac{\mu}{\sigma}\right)^{2}}}}$ expresses the

average increment of the real level to the basic level.

And the variance of the real level $\mathrm{X}$ is as follows:

$$
D(X)=\sigma^{2}+E(X)[\mu-E(X)]
$$

Thus, $\sigma$ or $\sigma / \mu$ can evaluate the basic development power, and $\sqrt{D(X)}$ or $\sqrt{D(X)} / E(X)$ can evaluate the real development power.

\subsection{The Economic Analysis based on Development power and Partial Distribution}

\subsubsection{Economic Growth is a General and Basic Trend}

Let $X_{i}$ follow a partial distribution, $i=1, \cdots$. Suppose that $X_{i}$ is the real level of $i$ th stage in a economic process, and $X_{i} \in$ $P\left[E\left(X_{i-1}\right), D\left(X_{i-1}\right)\right], E\left(X_{0}\right)=\mu, D\left(X_{0}\right)=\sigma^{2}, i=1, \cdots$.

From (2) and (3), we have, $E\left(X_{i}\right)>E\left(X_{i-1}\right)>\cdots>E\left(X_{0}\right)$, $R\left(X_{i}\right)<R\left(X_{i-1}\right)<\cdots<R\left(X_{0}\right)$ and $D\left(X_{i}\right)<D\left(X_{i-1}\right)<\cdots<D\left(X_{0}\right)$. These indicate that, if all the economic system, integrated environments and asset quality do not change, $E\left(X_{i}\right)>E\left(X_{i-1}\right)>$ $\cdots>E\left(X_{0}\right)$ means that the real level in economy will get higher and higher; $R\left(X_{i}\right)<R\left(X_{i-1}\right)<\cdots<R\left(X_{0}\right)$ means the increment of economic output will get lower and lower; $D\left(X_{i}\right)<D\left(X_{i-1}\right)<\cdots<D\left(X_{0}\right)$ means the real development power will be released continuously, and economic production will approach to a stabile status or equilibrium. These indicate that economic growth is a general and basic trend. But, in a certain period of time, the growth process will go to its end when development power is released sufficiently. We need to accumulate a new development power, such as new policies, new techniques, etc., in order to go to a new economic growth process.

\subsubsection{The Economic Cycle Depends on the Movements of Development Power}

As we know, a derivative process includes an accumu-lating process and a releasing process of development power. Furthermore, growth process includes the growths with ac-cumulation and release of development power, and a recession process includes the recessions with accumulation and release of development power. A whole growth process is similar to a whole recession process in structure, but development power moves in a reverse 
direction. These could be shown in Fig. 4.

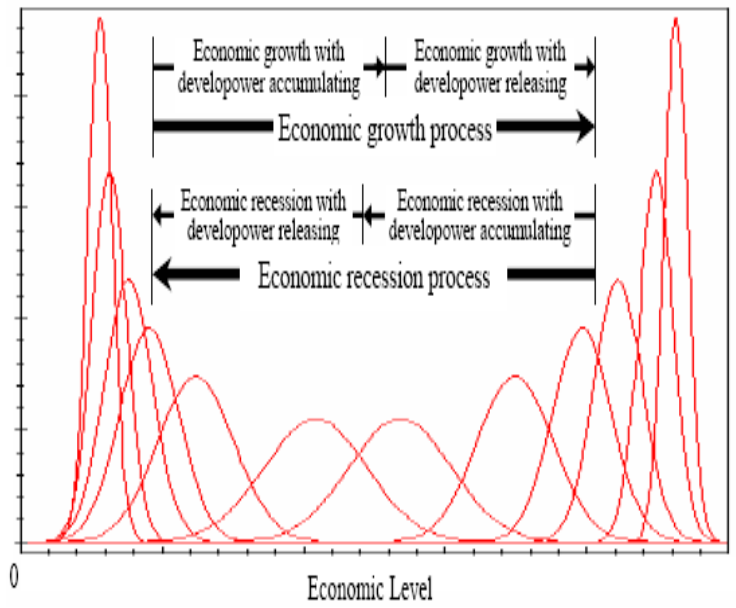

Figure 4. The structure of a derivative process based on the partial distribution. In the economic growth with development power accumulating, development power changes from smaller to larger; and in the economic growth with development power releasing, development power changes from larger to smaller. To the recession process, we have the reverse depiction.

In Fig. 4, the notations are as follow:

$\mu_{i}$ - the basic level of $i$ th stage.

$\sigma_{i}$ - the basic development power of $i$ th stage.

We could replace $\sigma_{i}$ by $v_{i}=\sigma_{i} / \mu_{i}$ if needed.

$X_{i}$ - the real level of $i$ th stage, $X_{i} \in P\left(\mu_{i}, \sigma_{i}^{2}\right)$.

$f\left(x_{i}\right)$ - the probability density of $x_{i}$, see also (1).

In the economic growth, the direction is from left to right. Development power is smaller at the beginning, and gets larger and larger, and this is the growth with the accumulation of development power; after development power has been accumulated to a higher degree, it will become smaller and smaller, and this is the growth with the release of development power. In the recession process, there is a reverse depiction. So we see there is a moving cycle of development power in economic growth or recession.

\section{The Empirical researches}

In this section, we will illustrate that the development power and derivative process can be described.

\subsection{Data and Notations}

Here we take U.S. GDP (chained) price indexes (Date source Web, http://www.whitehouse.gov, and the GDP index for short) as the samples to evaluate the productivity and development power. Though US economy has been growing from end of World War II to 2004, development power fluctuates always. There are many different characteristics of development power in this period. We have the notations and expressions as follow:

$\mu(\mathrm{t})$ - The basic level of the year $\mathrm{t}, \mathrm{t}=1940,1941, \cdots, 2005$, measured by the GDP index.

$v(t)$ - The development power index of the year $t$, measured by the fluctuating ratio of the basic level. $v(t)=|\mu(t)-\mu(t-1)| / \mu(t), t=1941,1942, \cdots, 2005$.

$\mathrm{X}(\mathrm{t})$ - The real level of the year $\mathrm{t}$, a non-negative stochastic variable. $\mathrm{X}(\mathrm{t}) \in \mathrm{P}(\mu(\mathrm{t}),[\mathrm{v}(\mathrm{t})] 2)$.

where, $\mu(t+1)=X(t)(t=1940,1941, \cdots, 2004)$. These mean the real level will be the basic level of next stage. In the following discussion, we do not distinguish the development power and development power index.

The time unit for sampling data GDP is a year, the stability of data is higher, and the difference between GDP price index of one year and that of last year can nicely describe the economic fluctuation, so we adopt the formulas of $v(t)$ mentioned above. The curves of development power and real level of U.S. economy are shown in Fig. 5.

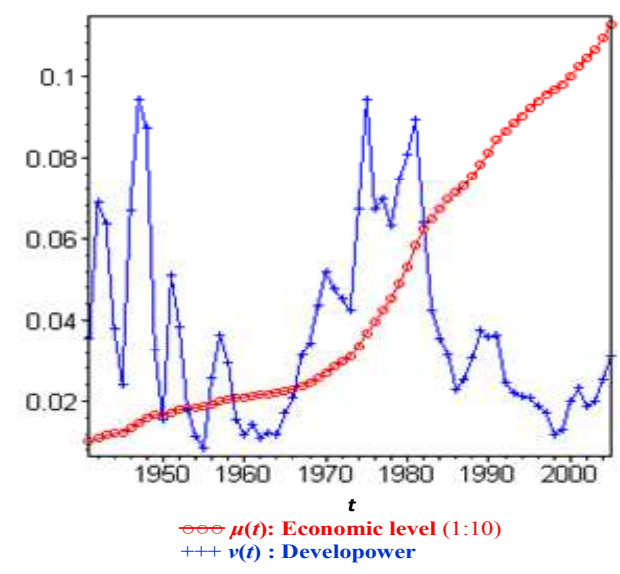

Figure 5.The curves of U.S. economic level $\mu(t)$ and development power $v(t)$ in the time period from 1941 to 2005. $\mu(t)$ is valued by GDP (chained) price index (Fiscal Year 2000=1.000). The proportion of the drawn indexes of $\mu(t)$ to the real indexes is $1: 10$. Though economic level $\mu(t)$ has been growing, development power fluctuates always.

\subsection{Development Power Movements and Derivative Process in U.S. Economic Development}

We see, from Fig. 5, the economic development power would go down if it is higher, namely development power will release if it is accumulated to a certain degree. Also, the development power will accumulate if it is released to a certain degree.

In Fig. 6(a), we draw the partial distribution curves of $\mathrm{X}(\mathrm{t})$ according to local top values of $\mathrm{v}(\mathrm{t})$ on the years $(\mathrm{t}=1947$, 1951, 1957, 1961, 1970, 1977, 1981, 1989, 2001, 2005).

According to Fig. 6(a), U.S. economic growth from 1942 to 2004 can be divided as three phases below.

First phase: 1942-1963, there is an economic growth with the release of development power.

Second phase: 1963-1975, there is an economic growth with the accumulation of development power.

Third phase: 1975-2004, there is also an economic growth with the release of development power.

In order to check the characteristic of derivative processes that exist in economic development, we also draw the partial distribution curves of $\mathrm{X}(\mathrm{t})$ according to local bottom values of $v(t)$ on the years $(t=1941,1945,1950,1955,1962,1973$, 
1978, 1986, 1998, 2003) in Fig. 6(b).

In Fig. 6 (b), U.S. economic growth from 1941 to 2003 can be divided as four phases below.

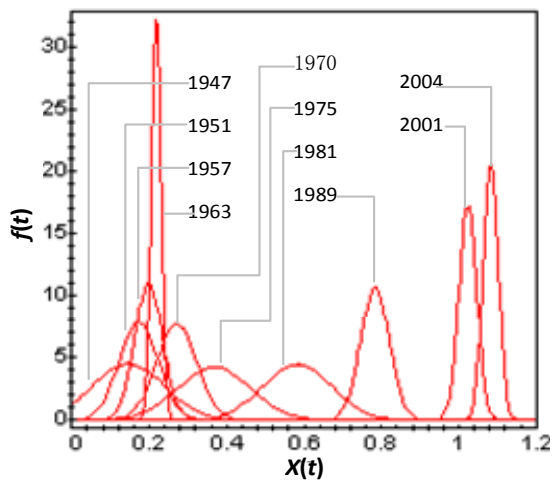

(a)

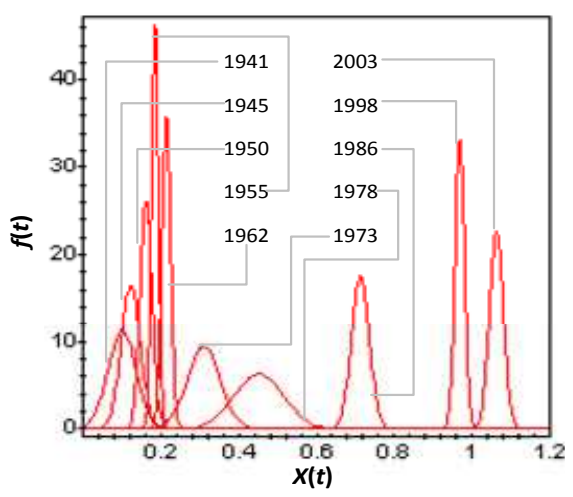

(b)

Figure 6. (a) The partial distribution curves of economic level $X(t)$ at the years of local top points on development power. The periods of time 1947 1963 and 1975 2004 are the economic growth with development power releasing, and in the period of time 1963 1975, there is an economic growth with development power accumulating. (b) The partial distribution curves of economic level $X(t)$ at the years of local bottom points on development power. The periods of time 1941 1955 and 1978 1998 are the economic growth with development power releasing, and in the periods of time 1955 1978 and 1998 2003, there are two economic growth processes with development power accumulating.

First phase: 1941-1955, there is an economic growth with the release of development power.

Second phase: 1955-1978, there is an economic growth with the accumulation of development power.

Third phase: 1978-1998, there is also an economic growth with the release of development power.

Fourth phase: 1998-2003, there is also an economic growth with the accumulation of development power.

In Fig. 6 (a) and (b), we do not show the development power movements between 1986 and 1998. If drawing the distribution curves of $X(t)$ these 13 years, we have Fig. 7 (a).

There is another whole derivative process in Fig. 7(a), includes an economic growth with the accumulation of development power and an economic growth with the re-lease of development power. There are the similar devel-opment power movements between 1998 and 2003, see also Fig. 7(b)

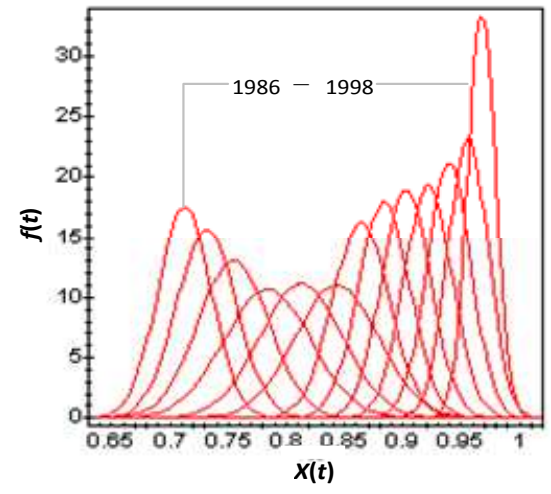

(a)

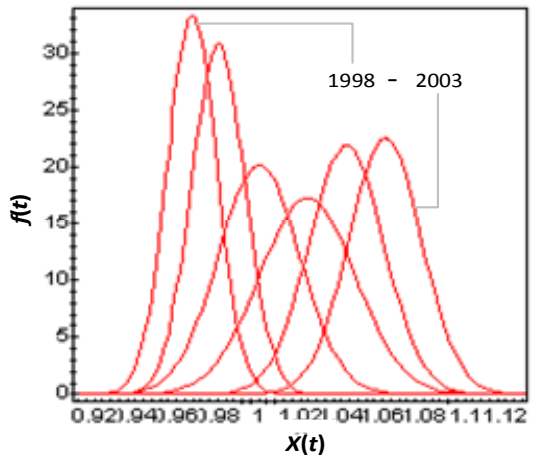

(b)

Figure 7. (a) The curves of partial distribution on development power movements between 1986 and 1998. This is a whole derivative process in a smaller scale. (b) The curves of partial distribution on development power movements between 1998 and 2003. This is also a whole derivative process in a smaller scale.

Summing up the above empirical researches, we obtain a conclusion that the development power movements and derivative process exist always in the economic develop-ment. Their macroscopic structure are similar generally, and the differences in derivative processes are the time span.

\subsection{An Summary}

From the above analysis, we see that there are develop-ment power movements in economic process. In addition, there are two phenomenon needed to indicate:

(i) The economy may grow in advance, i.e., economy may start growing in the middle or later period of devel-opment power accumulation.

(ii) The development power in U.S. economy is at a lower degree. Because development power cannot release infi-nitely, U.S. economy may start a larger scale of accumula-tion of development power around 2010, and is corroborated in literatures $[19,20,21,22]$. This process should be an economic growth with the accumulation of development power, or an economic recession with the accumulation of development power. In order to avoid the economic recession, U.S. government needs to do a lot of 
innovation works, such as, economic innovation, technology innovation, policy innovation, system innovation, market innovation, financial innovation, education innovation, management innovation, cultural development, etc. If like that, U.S. economy may keep on growing stably in next decade or more.

\section{Concluding Remarks}

In this paper, we focus on the development power and its theoretical frame. The theory thinks that the real dynamics to promote the economy growth is the development power in economic environments. Though the development power, such as policy development power, scientific development power, etc. does not increase directly economic output itself, they can efficiently promote to improve the productivity, and push economy to grow. Therefore, it is important for us to study development power.

In addition, using the models (1)-(3), we can describe development power movements in the process of economic development, and analyze the scale of the economy cycle, evaluate the status of economic development, establish the suitable policies for economic development and lead eco-nomic development in a positive way.

Some problems which are worth to study further about development power and derivative process are listed as follows:

(1) The theoretical system of development power needs to be developed and perfected further.

(2) The empirical analysis and research on development power need to be made further.

(3) The researches on policy development power, scientific development power and other development powers should be done further.

(4) More evaluating methods for development power should be put forward, in order to describe and analyze the macroeconomic problems more accurately.

\section{References}

[1] R. E. Lucas, "Understanding business cycles," Studies in Business Cycle Theory, MIT Press, Cambridge, Mass., 1981, pp. 215-239.

[2] R. E. Lucas, "Models of Business Cycles," Basil Blackwell, New York. 1987.

[3] F. Kydland and E. Prescott, "Time to Build and Aggregate Fluctuations," Econometrica, vol. 50, pp. 1345-1370, 1982.

[4] P. M. Romer, "Increasing Returns and Long-run Growth," Journal of Political Economy, vol. 94, pp. 1002-1037, 1986.

[5] P. M. Romer, "Cake Eating, Chattering, and Jumps: Existence Results for Variational Problems," Econometrica, vol. 54, pp. 897-908, 1986.

[6] P. M. Romer, "Endogenous technological change," Journal of Political Economy, vol. 98, pp. 71-102, 1990.

[7] D. Kahneman, and A.Tversky, "Prospect Theory: An
Analysis of Decision under Risk," Econometrica, vol. 47, pp. 263-291, 1979.

[8] R. E. Lucas, "On the mechanics of economic development," Journal of Monetary Economics, vol. 22, pp. 3-42, 1988.

[9] J. Long and C. Plosser, "Real Business Cycles," Journal of Political Economy, vol. 91, pp. 39-69, 1983.

[10] C. Plosser, "Understanding Real Business Cycles," Journal of Economic Perspectives, vol. 3, pp. 51-77, 1989.

[11] R. King, C. Plosser, and S. Rebelo, "Growth and Business Cycles: I \&II," Journal of Monetary Economics, vol. 21, pp. 195-232, 309-341, 1988.

[12] R. E. Lucas, "Econometric Policy Evaluation: A Critique," Carnegie-Rochester Conference Series on Public Policy, vol. 1, pp. 19-46, 1976.

[13] H. A. Simon, "Rational choice and the structure of the envi-ronment," Psychological Review, vol. 63, pp. 120-138, 1954.

[14] D. Kahneman, J. L. Knetsch, and R H. Thaler, "Fairness and the Assumptions of Economics," Journal of Business, vol. 59, pp. 285-300, 1986.

[15] A. Tversky, P. Slovic, and D. Kahneman, "The Causes of Preference Reversal,” American Economic Review, vol. 80, pp. 204-217, 1990.

[16] F. Dai, S. T. Wu, and Z. F. Qin, "The Latent Dynamics for Industry Progress: Development Power in Management and Its Derivative process Models," Chinese Journal of Man gement and Its Derivative process Models," Chinese Journal of Management Science, vol. 12, pp. 551-554, 2004.agement Science, vol. 12, pp. 551-554, 2004.

[17] F. Dai and Z. F. Qin, "DF Structure Models for Options Pricing," ICFAI Journal of Applied Economics, vol. 4, pp. 61-77, 2005.

[18] F. Dai, "DF Structure Models for Options Pricing on the Dividend-Paying and Capital-Splitting," ICFAI Journal of Applied Economics, vol. 6, pp. 17-30, 2007.

[19] F. Dai and J. P. Du, "Economic Growth and Control Strategies under the Environmental Pressure: Economic Advance-Retreat Course Analysis II," International Journal of Management Science and Engineering Management, vol. 3, pp. 33-53, 2008.

[20] F. Dai, J. X. Liu, and H. Liu, "Balance conditions and control strategies for economic growth: Economic Advance-Retreat course analysis III," International Journal of Management Science and Engineering Management, vol. 4, pp. 20-38, 2009.

[21] F. Dai, J. P. Qi, and L. Liang, "Socio-Economic Development Model Based on Stochastic Advance-Retreat Course: An Analysis on U. S. Economy in Recent 70 Years," International Journal of Social Economics, vol. 38, pp. 416-437, 2011.

[22] F. Dai, L. Liang, X. B. Li, and J. T. Feng, "The Dynamic Advance-Retreat Course Model for Economic Growth and the Empirical Research," Chinese Journal of Management Science, vol. 20, pp. 400-403, 2012.

[23] R. E. Lucas, "Understanding business cycles," Studies in Business Cycle Theory, MIT Press, Cambridge, Mass., 1981, 
pp. 215-239.

[24] R. E. Lucas, "Models of Business Cycles," Basil Blackwell, New York. 1987.

[25] F. Kydland and E. Prescott, "Time to Build and Aggregate Fluctuations," Econometrica, vol. 50, pp. 1345-1370, 1982.

[26] P. M. Romer, "Increasing Returns and Long-run Growth," Journal of Political Economy, vol. 94, pp. 1002-1037, 1986.

[27] P. M. Romer, "Cake Eating, Chattering, and Jumps: Existence Results for Variational Problems," Econometrica, vol. 54, pp. 897-908, 1986.

[28] P. M. Romer, "Endogenous technological change," Journal of Political Economy, vol. 98, pp. 71-102, 1990.

[29] D. Kahneman, and A.Tversky, "Prospect Theory: An Analysis of Decision under Risk," Econometrica, vol. 47, pp. 263-291, 1979.

[30] R. E. Lucas, "On the mechanics of economic development," Journal of Monetary Economics, vol. 22, pp. 3-42, 1988.

[31] J. Long and C. Plosser, "Real Business Cycles," Journal of Political Economy, vol. 91, pp. 39-69, 1983.

[32] C. Plosser, "Understanding Real Business Cycles," Journal of Economic Perspectives, vol. 3, pp. 51-77, 1989.

[33] R. King, C. Plosser, and S. Rebelo, "Growth and Business Cycles: I \&II," Journal of Monetary Economics, vol. 21, pp. 195-232, 309-341, 1988.

[34] R. E. Lucas, "Econometric Policy Evaluation: A Critique," Carnegie-Rochester Conference Series on Public Policy, vol. 1, pp. 19-46, 1976.

[35] H. A. Simon, "Rational choice and the structure of the envi-ronment," Psychological Review, vol. 63, pp. 120-138, 1954.

[36] D. Kahneman, J. L. Knetsch, and R H. Thaler, "Fairness and the Assumptions of Economics," Journal of Business, vol. 59, pp. 285-300, 1986.
[37] A. Tversky, P. Slovic, and D. Kahneman, "The Causes of Preference Reversal," American Economic Review, vol. 80, pp. 204-217, 1990.

[38] F. Dai, S. T. Wu, and Z. F. Qin, "The Latent Dynamics for Industry Progress: Development Power in Management and Its Derivative process Models," Chinese Journal of Man gement and Its Derivative process Models," Chinese Journal of Management Science, vol. 12, pp. 551-554, 2004.agement Science, vol. 12, pp. 551-554, 2004.

[39] F. Dai and Z. F. Qin, "DF Structure Models for Options Pricing," ICFAI Journal of Applied Economics, vol. 4, pp. 61-77, 2005.

[40] F. Dai, "DF Structure Models for Options Pricing on the Dividend-Paying and Capital-Splitting," ICFAI Journal of Applied Economics, vol. 6, pp. 17-30, 2007.

[41] F. Dai and J. P. Du, "Economic Growth and Control Strategies under the Environmental Pressure: Economic Advance-Retreat Course Analysis II," International Journal of Management Science and Engineering Management, vol. 3, pp. 33-53, 2008.

[42] F. Dai, J. X. Liu, and H. Liu, "Balance conditions and control strategies for economic growth: Economic Advance-Retreat course analysis III," International Journal of Management Science and Engineering Management, vol. 4, pp. 20-38, 2009.

[43] F. Dai, J. P. Qi, and L. Liang, "Socio-Economic Development Model Based on Stochastic Advance-Retreat Course: An Analysis on U. S. Economy in Recent 70 Years," International Journal of Social Economics, vol. 38, pp. 416-437, 2011.

[44] F. Dai, L. Liang, X. B. Li, and J. T. Feng, "The Dynamic Advance-Retreat Course Model for Economic Growth and the Empirical Research," Chinese Journal of Management Science, vol. 20, pp. 400-403, 2012. 